\title{
The day a tsetse fly landed in the tuberculosis ward
}

\begin{abstract}
A sepia brown fly, five times bigger than a mosquito, hovers like a helicopter over the face of the sickest man in the tuberculosis ward. Time stops. The susurration of alarm and despondency that passes through the ward heralds an approaching danger. "Tsetse fly!" declares the head nurse of the male ward, a veteran of the King's African Rifles. He had served as a dresser in Egypt during World War II and had got to know all the pests that carry disease on the road between West Africa and the Middle East. Pausing over the patient, he waits for the fly to alight on the man's cheek, seizes it and holds it up for me to admire. "Tsetse fly," he announces again, this time smiling at his accomplishment. He shows me its efficient proboscis, designed for sucking a meal of vertebrate blood every three or four days. We examine the delicate wings, a little frayed at the rear edge, showing the fly's age. They fold neatly along the length of its body like the blades of scissors. The second, longitudinal vein does not branch. The cell formed between the third and the fourth veins resembles a tiny sabre. "Tsetse fly," I agree, and the nurse crushes it between his thumb and forefinger. In the bright morning sun the fly must have left its perch on the shady, lower foliage of a nearby tree, investigating our movement, in the expectation of a meal, as we walked from the male ward to the tuberculosis ward. At the time it seemed like just another little incident in a busy day, but the scene still recurs to me after all these years, as if it waits to reveal its significance.

The one-doctor hospital I ran was in Nigeria, in a rural village at the centre of former Biafra, still reeling from the destruction of the war. Reconstruction was on everyone's mind, but it was slow to happen because of extreme poverty and inadequate government funding. The hospital ran on its own meagre revenue; if we could not afford it, we could not offer it.
\end{abstract}

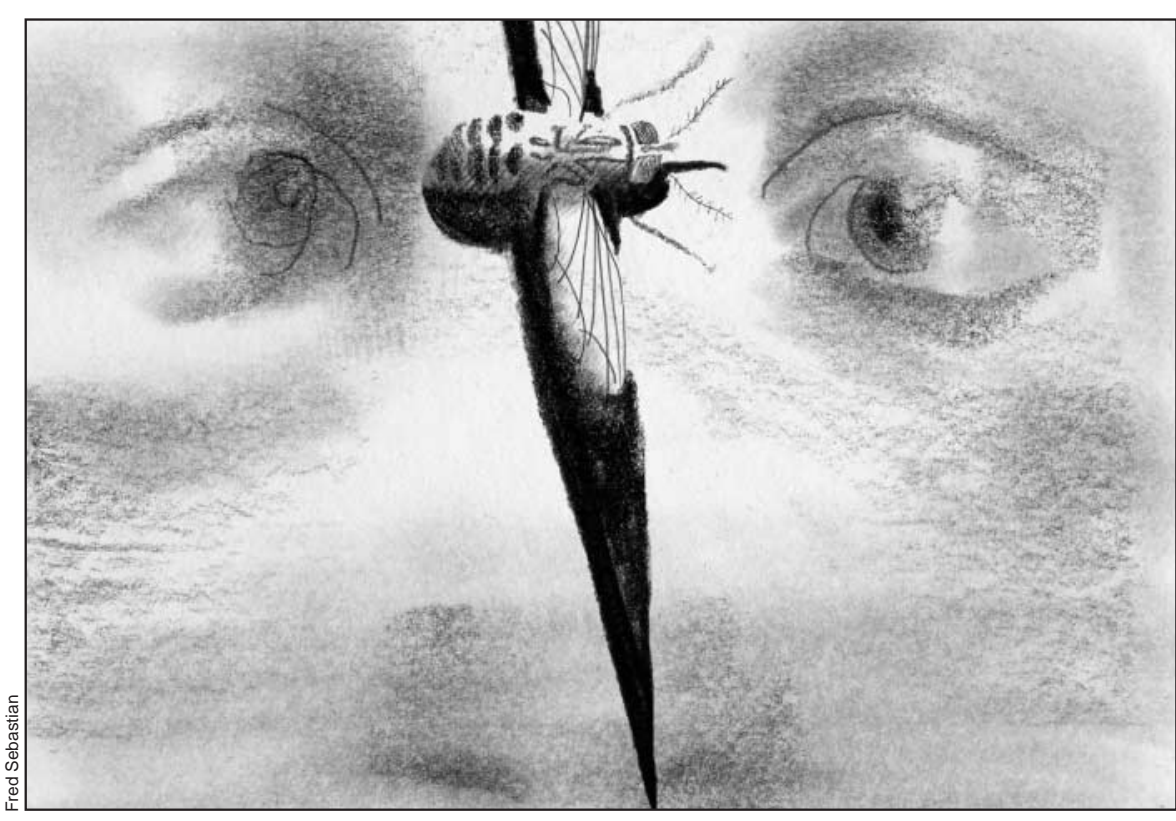

"Tuberculosis is a disease of poverty," Norman Bethune once wrote. After a few short months of sorting through the throng who awaited me at the outpatients' clinic each morning, I was convinced of the truth of this. Tuberculosis is also a wasting disease. Some came walking, but more arrived in a bicycle basket or on a litter, brought by a family member desperate to help but uncertain where to turn. They were nearly always children or young adults, but their age was hard to guess; most resembled mummies more than they did the living. They came late because they were unable to afford even our low-cost, low-tech care. Bloody and purulent sputum, scrofulous drainage at the side of the neck or at an axillary fistula working its way through from the adjacent apical lung abscess, made the diagnosis by acid-fast stain straightforward. The treatment was not, for these patients did not routinely survive with a drug prescription alone. Some could not afford the drugs; others took the pills, forgoing food to purchase them; still others wanted one injection that might effect a magic cure. We would never see these last again.
Reconstruction has to begin on a local scale. After some scrounging and a little funding, an unused storage shed was reroofed, doors were hung and the screens on the open half-walls were repaired. We could treat up to four men and four women at once. A basic diet with a lot of calories was somehow provided. From this point on, treatment for tuberculosis was offered only to those who agreed to stay in the new ward for at least four weeks. Directly observed treatment was the rule, years before anyone had coined the term. The new set-up seemed to provide security and comfort for the most desperate; few died who entered there. Everyone in the hospital was gratified by the accomplishment.

This was all a long time ago, but still the image of that fly, that patient, that day, recurs. Why? Is it because our special provision for exceptional care had been breached by a mere insect? Is it because the tsetse fly went for the sickest among the most vulnerable: a tubercular man already invaded by acid-fast bacillus was now attacked by a blood-thirsty insect whose salivary glands might contain, in addition 
to anticoagulant, the deadly trypanosomes? Or is it because I was reminded that nature can be truly cussed, apt to inflict misery at random? More generally, do we have the life we have created for ourselves, or the one that fate has visited upon us? Is it a case of "As you like it," or "Like you 'as it"? The man in the tuberculosis ward, the threatening tsetse fly, flash before me. Was he responsible for his situation? Was I? Are we? I thought that I grasped it then, but now I no longer know for certain. The causes of so many of the disease predicaments I was faced with seem now to be so complex.

The dallying between predicaments wrought through cause and the others wrought by chance seems to be part of everyday medical practice. For our patients - and for us, too - day-to-day experience brings such a curious mixture of choices that we can freely make and of surprising happenings that we can only live through. Between cause and chance, we live the humdrum of each day, hoping to grow and dreading to die - perhaps from the fateful bite of some fearful bug. Given the cause, most of us will choose to act; given chance, we can only respond. By cause we live; through chance we grow.

\section{Kenneth M. Flegel}

Professor, Division of General Internal

Medicine

McGill University

Montréal, Que.

Associate Editor, CMAJ

\section{Lifeworks}

\section{A mark on his body, a mark on us}

$\mathrm{T}$ heodore Wan marked his own body and placed himself at the centre of his most powerful images. In a series of medical and dental photographs taken at Dalhousie University's medical school and faculty of dentistry in Halifax, the photographer played the patient. In so doing, he created work with a powerful dual nature. The photographs included in the Dalhousie Art Gallery's recent posthumous survey of Wan's work from the 1970s and 1980s illustrate our complex relationship with our own bodies. On the one hand, the body signifies strength, gives a sense of identity and is a source of pleasure. But through aging, illness and accident, the body is also vulnerable and, at times, may even elicit disgust.

Despite the inclusion of other bodyoriented work (such as those of nudists at Vancouver's Wreck Beach or of dancers in the city's strip clubs) created after his return to his hometown in 1980 , it is Wan's multiple series of medical and dental photographs that have the most powerful impact. Created with the full cooperation of the two university faculties, Wan's photographs were technically accurate and thus usable as visual aids in the education of young doctors and dentists. He spent a year as a staff photographer at the faculty of dentistry. At the same

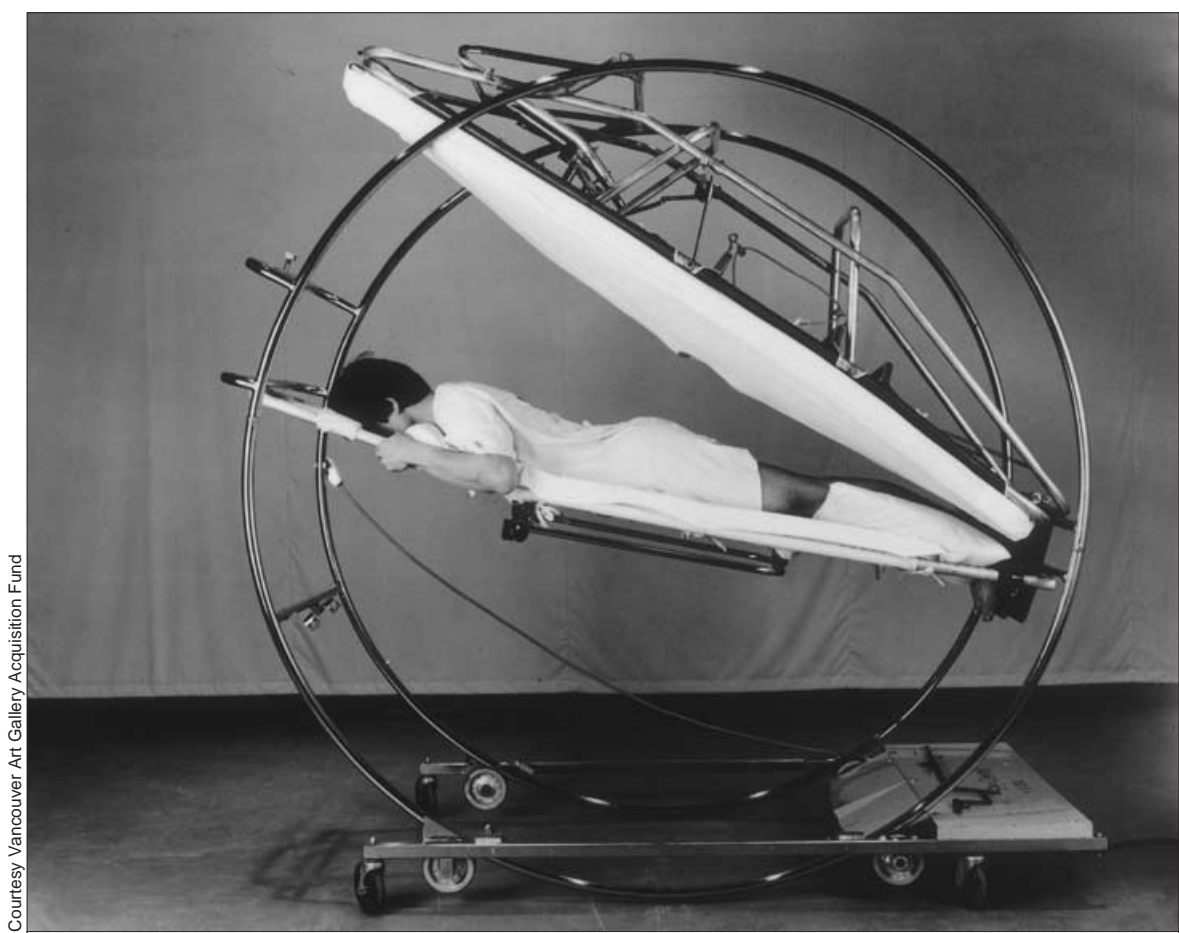

From the series, Bound by Everyday Necessities I (1979).

time, Wan's artistic sensibilities, honed while completing a Master's Degree in Fine Art at the Nova Scotia College of Art and Design (NSCAD) between 1975 and 1979, allowed him to apply a more subjective layer of meaning to his photographs. He recognized that all of us, at one time or another, must assume the role of patient. Often, health care procedures seem to be done not so much for us as to us.

This point is not lost on the show's curator, Christine Conley, a professor of visual arts at the University of Ottawa. Conley first met Wan and became familiar with his work in 1982, while, as a student at the University of Alberta, she worked at the university's 